Article

\title{
Influence of Temperature on the Performance of a Full-Scale Activated Sludge Process Operated at Varying Solids Retention Times Whilst Treating Municipal Sewage
}

\author{
Moazzam Shahzad ${ }^{1}$, Sher Jamal Khan ${ }^{1}$ and Parneet Paul ${ }^{2, *}$ \\ 1 Institute of Environmental Sciences and Engineering, School of Civil and Environmental \\ Engineering, National University of Sciences and Technology, Islamabad 44000, Pakistan; \\ E-Mails: moazzam.shahzad@gmail.com (M.S.); s.jamal@iese.nust.edu.pk (S.J.K.)
}

2 Water Sustainability Research Centre, Department of Mechanical, Aerospace, and Civil Engineering, Brunel University London, Uxbridge, Middlesex UB8 3PH, UK

* Author to whom correspondence should be addressed; E-Mail: parneet.paul@brunel.ac.uk; Tel.: +44-1895-265-435; Fax: +44-1895-274-000.

Academic Editor: Say-Leong Ong

Received: 29 November 2014 / Accepted: 12 February 2015 / Published: 2 March 2015

\begin{abstract}
In this study, the solid retention time (SRT) was varied with the ambient temperature for a full-scale municipal activated sludge plant with capacity of 200,000 PE (Population Equivalent) located in a humid sub-tropical environment. The effects of ambient temperature on treatment performance were investigated. Off-line samples were collected and analyzed from the treatment plant. The actual temperature variation during the study period was divided into three overlapping ranges and the SRT was adjusted accordingly with temperature in order to achieve the desired effluent quality. The plant's observed effluent quality and thereby its overall removal efficiency was evaluated in terms of measuring standard biochemical parameters. The results indicate that significant improvement in effluent quality can be obtained by applying the variable SRT (5-7 days) dependent on temperature variation.
\end{abstract}

Keywords: activated sludge process; performance evaluation; solids retention time; temperature variation 


\section{Introduction}

Based upon archeological evidence, the Mohenjo-Daro Civilization of 1500 BCE (Before Common Era), in what is now modern day Pakistan, is considered the pioneer of the construction and operation of the earliest wastewater management system in the world [1]. Unfortunately, at present and like for most other developing countries, the wastewater management systems in modern day Pakistan are either improperly managed or non-existent. In a typical developing country, the municipal and industrial effluents are usually discharged into the river or nearest watercourse without any treatment and Pakistan is no exception in this case [2]. This practice is both environmentally unacceptable and obviously creates a potential threat to human and aquatic life alike [3]. In order to overcome this environmental pollution, more properly operated wastewater treatment plants are needed [4]. It has been reported that in Pakistan only 8\% of the effluent discharged from domestic and industrial sources receive any treatment [5]. An estimated $80 \%$ of untreated urban wastewater is used for crop irrigation in Pakistan [6]. In recent time the Environmental Protection Agency of Pakistan (Pak-EPA) has tried to address this serious issue by producing in 2001 a revised National Environmental Quality Standard (NEQS) that places emphasis on providing improved wastewater treatment, both in terms of countrywide coverage and in terms of technical appropriateness. As a result of this initiative a new Sewage Treatment Plant (STP-Phase IV) having capacity of 10 million gallons per day (mgd) based upon the activated sludge process (ASP) was established in Sector I-9 of Islamabad in 2009 [2]. ASP is a well established and proven wastewater treatment technique [7] and one of the most widely used biological treatments of wastewaters containing carbon and nitrogen pollutants [8].

Islamabad $\left(73^{\circ} 2 ' 24^{\prime \prime} \mathrm{E}, 33^{\circ} 25^{\prime} 48^{\prime \prime} \mathrm{N}\right)$, the capital city of Pakistan is characterized by a humid subtropical climate, with an average incoming wastewater temperature variation between 15 and $30{ }^{\circ} \mathrm{C}$ throughout the year. In a previous study conducted by Fatima and Khan [2] on the same activated sludge plant used in this current study, the solids retention time (SRT) of 7 days was found to be the optimum value for achieving maximum removal efficiency of chemical oxygen demand (COD), biochemical oxygen demand (BOD) and total suspended solids (TSS) during the colder winter months when microbial activity is at its lowest and treatment efficiency is usually at its worst. For simplicities sake, this plant was being operated throughout the year at the same SRT. However, it was noted that the plant treatment performance was found to decrease somewhat during hotter summer months even though it still met the revised NEQS.

The final goal of any treatment plant operator and process engineer is to achieve optimal effluent quality at minimal cost - that is usually difficult to achieve. It has been reported that two basic processes are essential when trying to maximize the performance of an activated sludge system [9]: (1) The transformation of particulate, colloidal and dissolved organic matter in the waste stream into suspended biomass; (2) The separation of the resulting biomass under the influence of gravity.

In the view of the effluent quality decline observed during the summer period, it was suggested that an analyses be carried out on how this temperature change exactly impacted upon treatment performance of this full scale plant. It is well known that microbial biomass activity, which is one of the controlling factors for efficient biological wastewater treatment is strongly correlated to ambient liquid temperature changes. Temperature variations not only impinge upon biological activities but also have a very strong impact on fluid viscosity, the maximum dissolved oxygen (DO) saturation 
levels, and on the settling velocity of biomass. It is not an economically feasible solution to control the aeration tank liquid temperature due to the high specific heat capacity of water; However, it is possible to adjust other parameters that are affecting biological and physico-chemical properties of the wastewater such as the wastage rate, which in turn controls the SRT [10].

Biological wastewater treatment plants, particularly ASPs, are generally designed on the basis of SRT (also known as sludge age) that represents the mean residence time of microorganisms in the biological reactor [11]. SRT is the key control parameter for the process responsible for maintaining "healthiness" of microorganisms [12]. The SRT is related to the growth rate of microorganisms and microbes that are able to reproduce themselves during this time can be detained and enriched in the system. Liao et al. [13] reported that the flocculating ability of sludge changes with respect to SRT and further implied the possibility of controlling biomass flocculation and separation by designing a suitable SRT. Microbial activity and population is significantly affected by variations in SRT that in turn is influenced by temperature [14]. SRT also has a significant impact on the operational costs of running a wastewater treatment plant (WWTP) [15]. It is generally recommended that a SRT for a conventional activated sludge process should be between 4 and 9 days in warmer climate $\left(15-25^{\circ} \mathrm{C}\right)[13,16-18]$ and 10 days or more in temperate zones $\left(>10^{\circ} \mathrm{C}\right)[11,19]$ where in addition to BOD removal, ammonium removal by nitrification and nitrate removal by denitrification will often also be required in order to meet more stringent effluent discharge standards. Short SRTs (less than 2-3 days) is not recommended because of dispersed growth of microorganisms creating poorly stabilized bio-flocs and causing poor effluent quality. On the contrary, long SRTs ( $>12$ days) can cause reduction in mean particle size suggesting pin floc formation or "ashing" [12].

Thus in an attempt to overcome the problem of relatively poorer treatment performance experienced during the summer period, the SRT was altered in this study based upon temperature variations occurring in the influent wastewater stream, and the plant treatment performance evaluated accordingly. Additionally this study measured the effect of varying the SRT on the settleability of the activated sludge in the secondary clarifier. Furthermore, this study also analyzed the effect of varying the SRT on the removal efficiency of secondary pollutants in the waste stream namely total nitrogen and total phosphorus. In some developing countries, it is also mandatory to remove these nutrients from plant effluent due to their toxicity and possible impact on marine life [20].

Research targeting a full-scale wastewater treatment process (WWTP) has rarely been attempted and results from lab scale experiments have proved difficult to extrapolate to real WWTP conditions [8]. One of the major issues when carrying out this study was that since a full scale plant treating urban wastewater was utilized, any applied control strategy had to meet the legal effluent discharge standards, i.e., NEQS for this plant. It was quite a bold endeavor to carry out research on an active full scale plant so thorough pre-planning was carried out so that both the plant operators and the respective environmental enforcement agency, i.e., Capital Development Authority (CDA) were fully involved and approved this research work from the outset.

\section{Materials and Methods}

The plant under study was a full-scale sewage treatment plant (STP) handling municipal wastewater that utilized an activated sludge system as a core part of the treatment process. The system comprised 
of three primary clarifiers, three aeration tanks, and three secondary clarifiers having total volumes of 5560,5400 , and $6450 \mathrm{~m}^{3}$, respectively. The capacity of the plant was to treat about $800 \mathrm{~m}^{3}$ of municipal wastewater per hour. In order to maintain the desired concentration of microorganisms in the bioreactor, the activated sludge from the secondary clarifier was recycled back into the aeration tank at the rate of about $640 \mathrm{~m}^{3}$ per hour, i.e., $80 \%$ of biomass recycle rate was maintained. In the aeration tank, the DO level was maintained between 1.5 and $2.5 \mathrm{~g} / \mathrm{m}^{3}$ with the help of low speed mechanical surface aerators. During the course of this study, the temperature of wastewater varied between 30 and $15{ }^{\circ} \mathrm{C}$ and the concentration of pollutants in the influent raw wastewater were as follows: $335-450 \mathrm{~g} / \mathrm{m}^{3}$ of TSS, $199-254 \mathrm{~g} / \mathrm{m}^{3}$ of COD, $112-150 \mathrm{~g} / \mathrm{m}^{3}$ of BOD, $96-125 \mathrm{~g} / \mathrm{m}^{3}$ of total organic carbon (TOC), 33-49 $\mathrm{g} / \mathrm{m}^{3}$ of total nitrogen (TN), 40-26 g/m $\mathrm{m}^{3}$ of ammonium-nitrogen $\left(\mathrm{NH}_{4}{ }^{+}-\mathrm{N}\right)$, and $49-33 \mathrm{~g} / \mathrm{m}^{3}$ of total phosphorous (TP). The mixed-liquor suspended solids concentration (MLSS) of the system was regulated between 3000 and $3500 \mathrm{~g} / \mathrm{m}^{3}$.

The SRT was regulated by the removal of excess sludge, with the help of sludge wastage pumps, which resulted in a variable MLSS concentration in the aeration tank. For this study, samples were taken from the inlet, the primary clarifier (at its outlet), the aeration tank (at its outlet) and in the final clarifier tank (at its outlet), three times per week over a five month period from September 2012 until January 2013. Samples were collected, transferred and analyzed in the laboratory as per recommendation of APHA et al. [21]. Samples were collected in 1 liter polyethylene bottles and afterward placed in an icebox to maintain a storage temperature of $4{ }^{\circ} \mathrm{C}$ before analysis on the same day. COD concentration was measured by closed reflux titrimetric methods. BOD concentration was measured by the dilution method while the TOC and TN levels were measured with a TOC/TN analyzer (Multi N/C 3100, Analytik Jena AG, Jena, Germany). $\mathrm{NH}_{4}{ }^{+}-\mathrm{N}$ and TP concentrations were determined with a spectrophotometer (DR 2010, HACH, Loveland, CO, USA). Sludge volume index (SVI) was used to evaluate the settleability of activated sludge according to Standard Methods [21].

\section{Results and Discussion}

\subsection{Selection of Solids Retention Time (SRT) Based upon Liquid Temperature Ranges}

In case of this specific activated sludge plant, the temperature profile of the incoming influent wastewater stream during the entire study period is given in Figure 1.

As can be seen there is an overall decrease of $15^{\circ} \mathrm{C}$ in the liquid temperature over a 150 day period. The temperature is decreasing because of the standard variations in the seasonal weather pattern experienced in Islamabad at this time of the year. The actual level of temperature drop experienced during these months is typical for this region of Pakistan. Based upon this anticipated seasonal variability, the actual temperature variation during the study period was divided into three overlapping ranges, and the SRT was adjusted accordingly. Hence the plant was either classified as being operated at the high temperature range of $25-30{ }^{\circ} \mathrm{C}$; Or the intermediate temperature range of $20-24{ }^{\circ} \mathrm{C}$; or finally at the low temperature range of $15-19^{\circ} \mathrm{C}$.

Before this investigation, the plant had been operating on a constant SRT of 7 days regardless of the time of year, as reported in Fatima and Khan [2]. In this previous study, the constant 7 days SRT was within optimal SRT range from 4 to 9 days [13,17]. Following this period of constant SRT, 
the SRT was varied according to the earlier established temperature ranges. Thus, it was operated for approximately 60 days at a SRT of 5 days during the high temperature range; subsequently it was operated for approximately a further 60 days at a SRT of 6 days during the intermediate temperature range; and finally, it was operated for approximately a final thirty days at a SRT of 7 days during the low temperature range. The respective SRT variation of 5, 6, and 7 days over the low, medium, and high liquid temperature ranges was based upon earlier bench scale activated sludge studies conducted by Andreadakis [16] where $\mathrm{BOD}_{5}$ removal and nitrification where optimally achieved at given SRT.

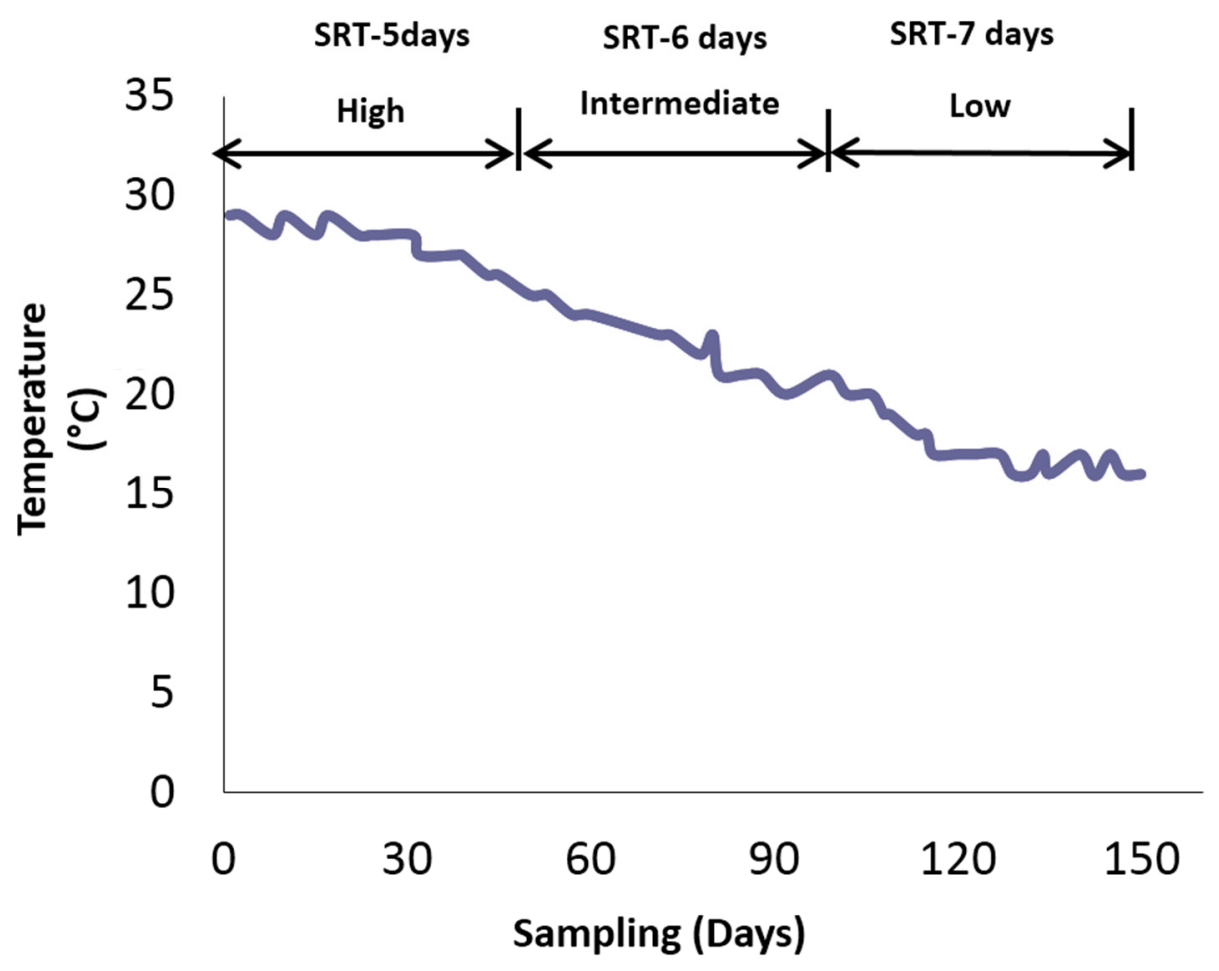

Figure 1. Temperature profile of wastewater treatment process (WWTP) from September 2012 to January 2013.

\subsection{Influence of Solids Retention Time (SRT) on Organic and Nutrients Removal}

Table 1 outlines the mean concentrations and mean removal efficiencies of various standard biochemical parameters measured in both the influent stream and effluent stream. After commencing this investigation that meant the plant was operated under a "dynamic" SRT regime, as can be seen in Table 1 there has been no deleterious impact on most of these biochemical parameters. In fact when comparing this plant's performance under this control strategy, the averaged effluent qualities achieved broadly match the anticipated effluent qualities of similar configuration activated sludge plant operated globally in similar circumstances as shown in Table 2.

The variation of the mean effluent concentration and the mean removal efficiency of the plant over a period of five months can be observed in the box-and-whisker plots shown in Figures 2 and 3, respectively (with specific biochemical parameter values shown in Table 1). 
These figures illustrate that a significant improvement can be observed in effluent quality and removal efficiency of the plant by varying the SRT as the environmental temperature dropped over the study period.

Table 1. Mean concentrations and removal efficiencies of the WWTP at variable Solids Retention Times (SRTs).

\begin{tabular}{cccccc}
\hline Parameter & Sampling Point (Units) & 7 Days $^{\text {a }}$ & 5 Days & 6 Days & 7 Days \\
\hline \multirow{4}{*}{ TSS } & Influent (mg/L) & 370 & 386 & 382 & 384 \\
& Effluent (mg/L) & 31 & 27 & 26 & 24 \\
& Removal efficiency (\%) & 91 & 93 & 93 & 94 \\
\hline \multirow{3}{*}{ BOD } & Influent (mg/L) & 133 & 131 & 135 & 132 \\
& Effluent (mg/L) & 29 & 24 & 23 & 21 \\
& Removal Efficiency (\%) & 77 & 82 & 82 & 82 \\
\hline \multirow{3}{*}{ COD } & Influent (mg/L) & 224 & 220 & 229 & 232 \\
& Effluent (mg/L) & 51 & 44 & 44 & 42 \\
& Removal Efficiency (\%) & 77 & 80 & 80 & 81 \\
\hline \multirow{4}{*}{ TOC } & Influent (mg/L) & 111 & 108 & 111 & 110 \\
& Effluent (mg/L) & 35 & 29 & 26 & 26 \\
& Removal Efficiency (\%) & 67 & 74 & 75 & 76 \\
\hline \multirow{3}{*}{ TN } & Influent (mg/L) & 38 & 39 & 43 & 38 \\
& Effluent (mg/L) & 18 & 22 & 21 & 18 \\
& Removal Efficiency (\%) & 52 & 46 & 48 & 53 \\
\hline \multirow{2}{*}{ TP } & Influent (mg/L) & 40 & 41 & 42 & 38 \\
& Effluent (mg/L) & 20 & 15 & 18 & 19 \\
& Removal Efficiency (\%) & 57 & 68 & 62 & 59 \\
\hline
\end{tabular}

Note: ${ }^{a}$ Initial SRT: Maintained by Fatima and Khan [2].

Table 2. Comparison of averaged observed and actual values of effluent concentration removal efficiencies.

\begin{tabular}{cccc}
\hline Parameter & Source & Effluent Concentration Range & Removal Efficiency Range \\
\hline \multirow{2}{*}{ TSS (mg/L) } & Literature $^{\text {a }}$ & 20 to 40 & 87 to 93 \\
& Actual $^{\text {b }}$ & 22 to 33 & 90 to 93 \\
\hline \multirow{2}{*}{ BOD (mg/L) } & Literature $^{\text {a }}$ & 10 to 40 & 85 to 97 \\
& Actual $^{\text {b }}$ & 21 to 30 & 77 to 85 \\
\hline \multirow{2}{*}{ COD (mg/L) } & Literature $^{\text {a }}$ & 30 to 120 & 80 to 93 \\
& Actual $^{\text {b }}$ & 41 to 55 & 76 to 82 \\
\hline \multirow{2}{*}{ TN (mg/L) } & Literature $^{\text {a }}$ & $>15$ & $<60$ \\
& Actual $^{\text {b }}$ & 16 to 26 & 43 to 53 \\
\multirow{2}{*}{ TP (mg/L) } & Literature $^{\text {a }}$ & $>04$ & $<60$ \\
& Actual $^{\text {b }}$ & 11 to 20 & 52 to 70 \\
\hline
\end{tabular}

Notes: ${ }^{a}$ Adapted from [22-27]; ${ }^{\mathrm{b}}$ Values obtained from five months study. 


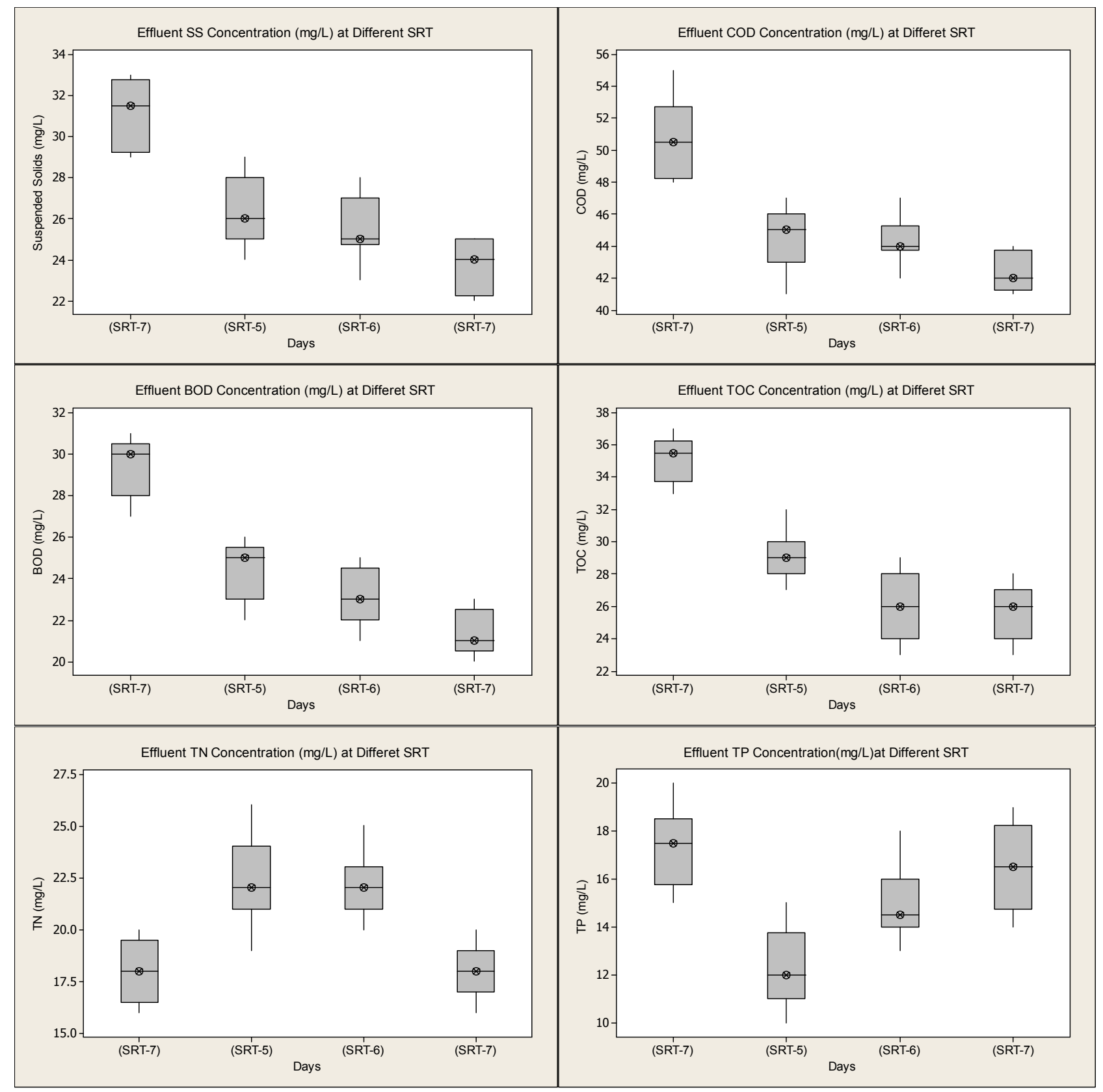

Figure 2. Effluent concentrations at different SRTs.

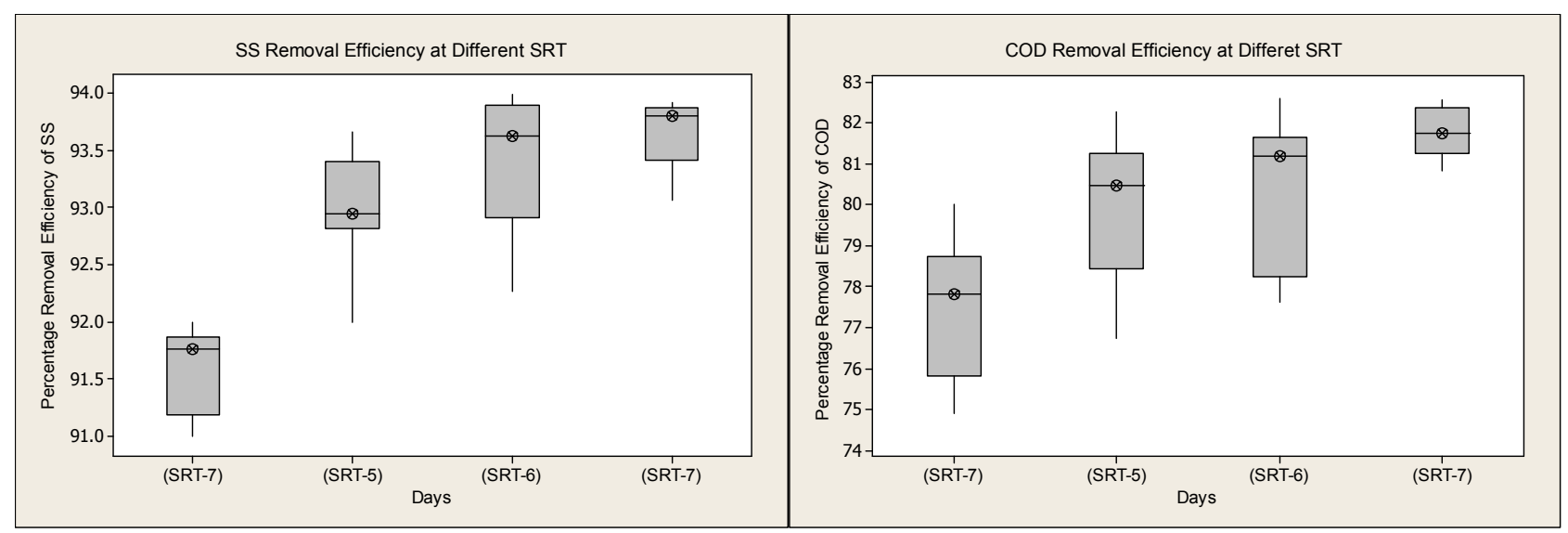

Figure 3. Cont. 


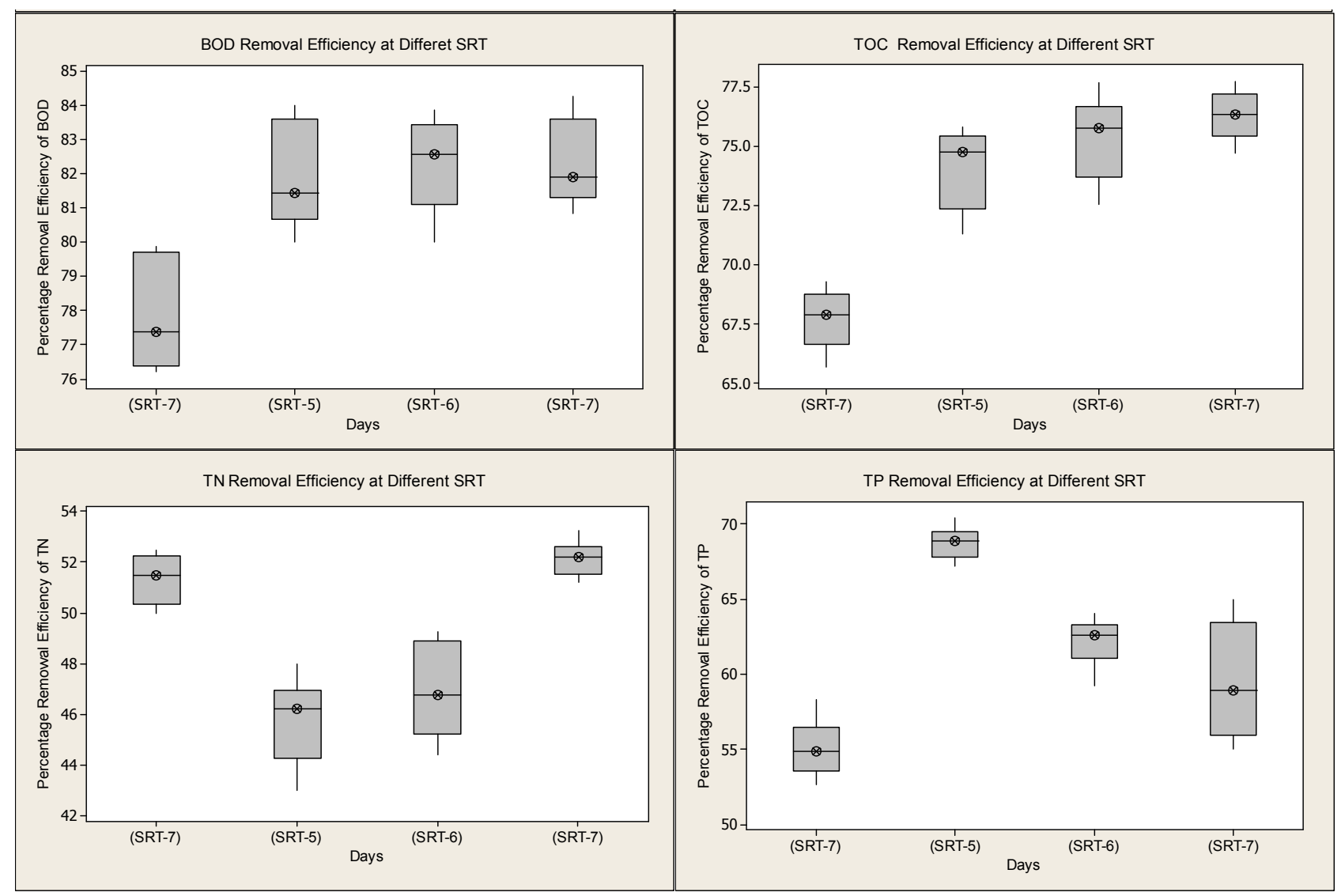

Figure 3. Removal efficiencies at different SRTs.

Looking at these improvements in effluent quality in more detail, it can be observed that when the SRT was dropped down to 5 days for the high temperature range of $25-30{ }^{\circ} \mathrm{C}$, the plant treatment performance was improved in terms of BOD, COD, TSS, TOC and TP when considering both removal efficiency and mean effluent concentration. However, in terms of TN, the plant treatment performance was reduced. This would be as expected, since reduced SRTs lead to less simultaneous nitrification and denitrification (SND) occurring in the structure of the aggregated sludge flocs leading to overall reduced TN removal. As the environmental temperature dropped further this TN removal rate slightly deteriorated as well. Thus, in order to maintain the required treatment performance, the SRT was raised to 6 days for the medium temperature range of $20-24{ }^{\circ} \mathrm{C}$. Once again it was observed that in terms of BOD, COD and TSS, the treatment performance was maintained but that the TP removal efficiency was significantly reduced. However this change in SRT control strategy had no significant impact on the observed TN removal efficiency. This increase in TP concentration can be attributed to the fact that the removal of phosphorous from wastewater involves the incorporation of phosphate into the MLSS and particularly into the phosphorus accumulating microorganisms (PAOs) and the subsequent removal of these solids via sludge wastage. A reduced wastage rate would naturally not decrease overall phosphorous levels [19]. With further drops in environmental temperature into the low temperature range of $15-19{ }^{\circ} \mathrm{C}$, the SRT was increased from 6 to 7 days to compensate for the perceived drop in microbial activity. Once again the same treatment performance was maintained in case of BOD, COD and TSS. Most importantly, the treatment performance was considerably improved in the case of TN since greater SND would be occurring in the sludge flocs. These TN results support 
the finding of Andreadakis [16] that complete nitrification in bench-scale activated sludge system was observed at SRT of 8 days and wastewater temperature of $15{ }^{\circ} \mathrm{C}$. However, in case of TP concentration, the plant's treatment performance was further reduced, although even in this instance it was much higher than the TP removal efficiency of other similar activated sludge plants operated globally. Again this further decrease in TP removal efficiency is mainly due to the reason that primarily less phosphorous is lost through the relatively low sludge wastage.

\subsection{Influence of Solids Retention Time (SRT) on Sludge Settling Properties}

For wastewater treatment processes, the SVI is a very useful parameter to use when indirectly measuring a treatment plant's performance. The SVI is a direct measure of the settling quality of the activated sludge. It is reported that if the SVI is equal to or less than $150 \mathrm{~mL} / \mathrm{g}$, the sludge has a very good settling characteristic whilst a SVI of above $150 \mathrm{~mL} / \mathrm{g}$ usually indicate the presence of filamentous bacteria, which prohibit floc settling [28]. Poor floc settling can lead to biomass washout with subsequent increased TSS levels in the effluent and reduced MLSS levels in the bioreactor leading to inefficient overall BOD, COD, and TSS removals. It is interesting to note that before initiating this control strategy, which adjusted the SRT accordingly, the plant's effluent quality was already meeting the NEQS but in terms of overall treatment efficiency its performance was still relatively poor. In fact even the sludge settleability proved poor as shown in Table 3 where for the initial pre-trial phase of this study at a SRT of seven days, the average value of SVI was $152 \mathrm{~mL} / \mathrm{g}$ for a MLSS average value of $3450 \mathrm{~g} / \mathrm{m}^{3}$ with the wastage sludge pump being operated for $8 \mathrm{~h}$.

Table 3. Effect of Temperature on sludge volume index (SVI).

\begin{tabular}{ccccc}
\hline Temperature Variation $\left({ }^{\circ} \mathbf{C}\right)$ & SRT (Days) & MLSS $\left(\mathbf{g} / \mathbf{m}^{\mathbf{3}}\right)$ & Wastage (Hour) & SVI (mL/g) \\
\hline $29-30^{\text {a }}$ & 7 & 3450 & 08 & 152 \\
$25-29$ & 5 & 3130 & 11 & 143 \\
$20-24$ & 6 & 3305 & 09 & 126 \\
$15-19$ & 7 & 3470 & 08 & 116 \\
\hline
\end{tabular}

Note: ${ }^{\text {a }}$ Initial SRT: Maintained by Fatima and Khan [2].

Figure 4 along with Table 3 both shows the impact of changing the SRT on the measured SVI values for the period under study. At the reduced SRT of 5 days, the average value of SVI was found to be $143 \mathrm{~mL} / \mathrm{g}$, and on average the MLSS concentration was maintained at $3130 \mathrm{~g} / \mathrm{m}^{3}$. At the increased SRT of 6 days, the average value of SVI was found to be an improved $126 \mathrm{~mL} / \mathrm{g}$ and the average value of the MLSS was maintained at an increased level of $3305 \mathrm{~g} / \mathrm{m}^{3}$. Finally, with the reestablishment of the SRT to 7 days during the coldest period, the average value of SVI was a very healthy $116 \mathrm{~mL} / \mathrm{g}$ and the average MLSS concentration was maintained at $3470 \mathrm{~g} / \mathrm{m}^{3}$. The temporal MLSS and mixed-liquor volatile suspended solids (MLVSS) concentrations over the three varying SRT conditions are shown in Figure 5. Previous studies have also reported that with enhanced nitrogen removal, the clarification in final settling tank also improves [16]. 


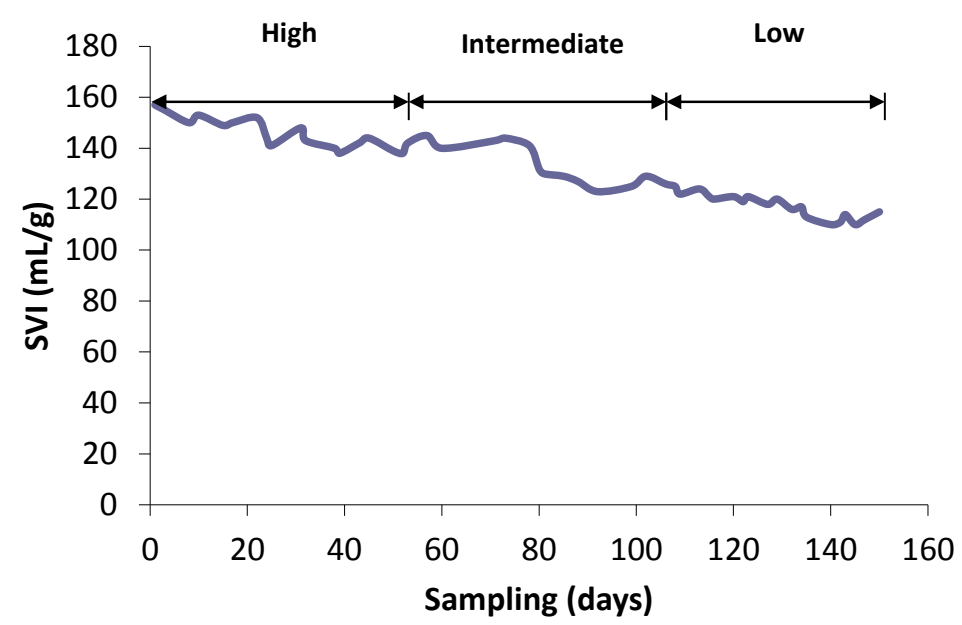

Figure 4. Variation of sludge volume index (SVI) during the study period.

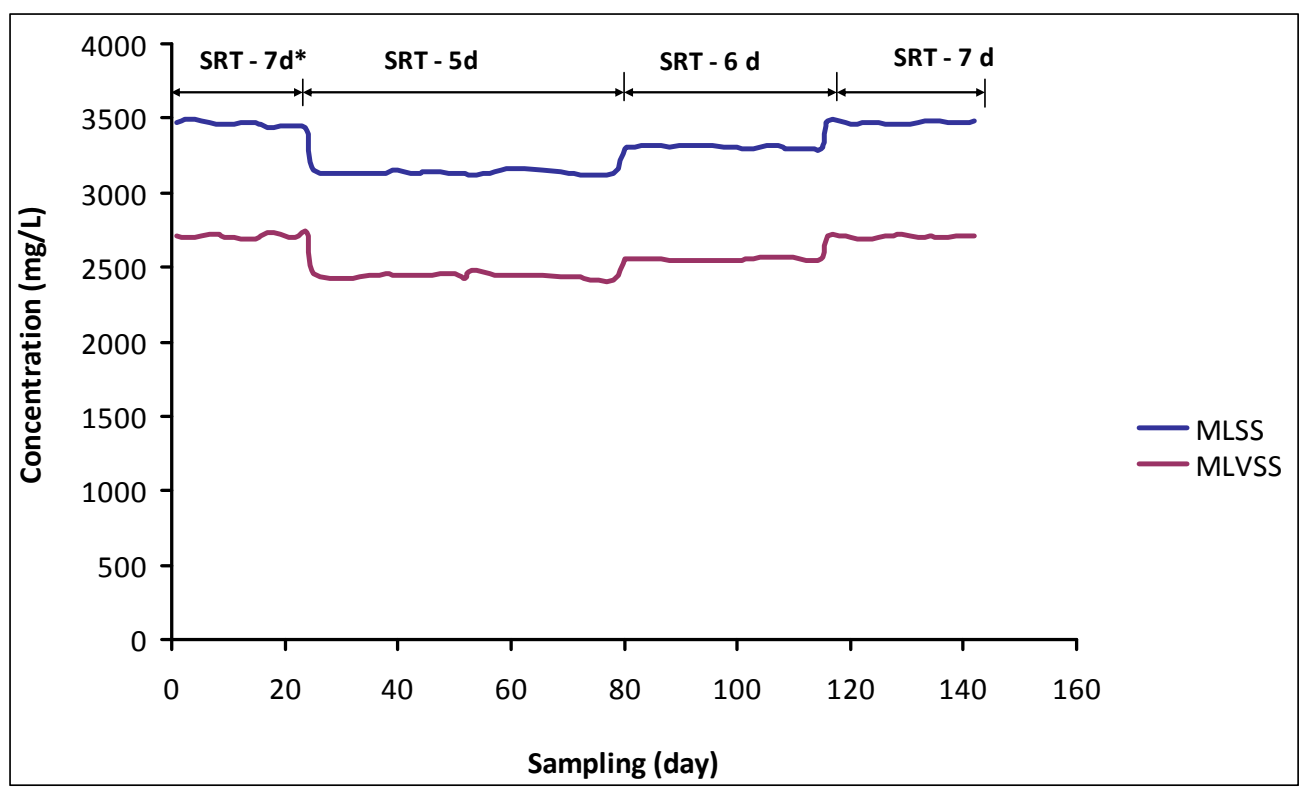

Figure 5. Temporal mixed-liquor suspended solids (MLSS) and mixed-liquor volatile suspended solids (MLVSS) concentrations during the study period. * Initial SRT: Maintained by Fatima and Khan [2].

Thus by initiating this SRT control strategy, not only does the plant treatment efficiency improve for the major biochemical parameters, but also the sludge quality in terms of its settleability since the measured SVI value reduces dramatically. However this improved settleability might be attributed to the drop in temperature since Sürücü and Çetin [9] found in their study that when the environmental temperature was gradually reduced in their plant, the solids settleability improved. Overall, higher SRT (5-7 days) contributed to superior effluent quality in terms of sedimentation supernatant and better settling rate as reported by earlier studies [13,17]. The dynamic SRT strategy while maintaining desired effluent quality, i.e., short SRT for warmer wastewater conditions and long SRT for temperate wastewater conditions, is also important from energy saving point of view as well. Increasing SRT generally increases energy consumption of wastewater treatment processes and reduces waste biomass production. Additional energy is required to provide the oxygen needed for nitrification and for the 
increased mass of biosolids endogenously respired [12]. It can be inferred that the energy requirement at longer SRT can be more than offset by energy savings associated with reduced biosolids production.

\section{Conclusions}

During this investigation it was found that in order to maintain the optimal performance of full scale activated sludge plant, the SRT should be changed with temperature in a "dynamic" way. Thus, after an increase in bacterial activity in summer, the SRT should be decreased in order to maintain acceptable treatment plant performance. However, as the wastewater temperature drops, and subsequent bacterial activity decreases, the SRT should be raised to maintain the same treatment performance. In conclusion, the results of this study indicate that a stable pollutant removal performance and effluent quality while minimizing energy requirements can be obtained by applying the temperature dependent dynamic SRT control strategy.

\section{Acknowledgments}

This work was supported by the Master of Science (MS) Research Grant provided by the National University of Sciences and Technology (NUST), Islamabad, Pakistan. The authors acknowledge the administrative and technical support provided by Shahid Suhail (former Director STP-CDA and current Member Engineering-CDA) and his support staff from Sewage Treatment Plant (STP), Capital Development Authority (CDA), Sector I-9, Islamabad, Pakistan.

\section{Author Contributions}

Moazzam Shahzad was a Master of Science (MS) student in Environmental Engineering and the research reported in this article was part of his MS Thesis. He was supervised by Sher Jamal Khan and co-supervised by Parneet Paul. The contributions of the author and co-authors are according to their role in this reported research work.

\section{Conflicts of Interest}

The authors declare no conflict of interest.

\section{References}

1. Wiesmann, U.; Choi, I.S.; Dombrowski, E.M. Fundamentals of Biological Wastewater Treatment: Fundamentals, Microbiology, Industrial Process Integration; Wiley-VCH Verlag GmbH: Weinheim, Germany, 2006.

2. Fatima, S.S.; Khan, S.J. Evaluating the treatment performance of a full scale Activated Sludge Plant in Islamabad. Water Pract. Technol. 2012, 7, 1.

3. Zhang, Z.; Li, H.; Zhu, J.; Weiping, L.; Xin, X. Improvement strategy on enhanced biological phosphorus removal for municipal wastewater treatment plants: Full-scale operating parameters, sludge activities, and microbial features. Bioresour. Technol. 2011, 102, 4646-4653.

4. Oliveira, S.C.; Sperling, M. Performance evaluation of different wastewater treatment technologies operating in a developing country. J. Water Sanit. Hyg. Dev. 2011, 1, 37-56. 
5. Sato, T.; Qadir, M.; Yamamoto, S.; Endo, T.; Zahoor, A. Global, regional, and country level need for data on wastewater generation, treatment, and reuse. Agric. Water Manag. 2013, 130, 1-13.

6. Ensink, J.H.J.; van Der Hoek, W.; Mara, D.D.; Cairncross, S. Waste stabilization pond performance in Pakistan and its implications for wastewater use in agriculture. Urban Water J. 2007, 4, 261-267.

7. Peng, G.; Ye, F.; Li, Y. Investigation of extracellular polymer substances (EPS)and physicochemical properties of activated sludge from different municipal and industrial wastewater treatment plants. Environ. Technol. 2012, 33, 857-863.

8. Kim, Y.M.; Cho, H.U.; Lee, D.S.; Park, D.; Park, J.M. Influence of operational parameters on nitrogen removal efficiency and microbial communities in a full-scale activated sludge process. Water Res. 2011, 45, 5785-5795.

9. Sürücü, G.; Çetin, F.D. Effects of temperature, $\mathrm{pH}$ and D.O. concentration on settleability of activated sludge. Environ. Technol. 1990, 11, 205-212.

10. Lippi, S.; Rosso, D.; Lubello, C.; Canziani, R.; Stenstrom, M.K. Temperature modelling and prediction for activated sludge systems. Water Sci. Technol. 2009, 59, 125-131.

11. Clara, M.; Kreuzinger, N.; Strenn, B.; Gans, O.; Kroiss, H. The solids retention time-A suitable design parameter to evaluate the capacity of wastewater treatment plants to remove micropollutants. Water Res. 2005, 39, 97-106.

12. Leu, S.Y.; Chan, L.; Stenstrom, M.K. Toward long solids retention time of activated sludge processes: Benefits in energy saving, effluent quality, and stability. Water Environ. Res. 2012, 84, $42-53$.

13. Liao, B.Q.; Droppo, I.G.; Leppard, G.G.; Liss, S.N. Effect of solids retention time on structure and characteristics of sludge flocs in sequencing batch reactors. Water Res. 2006, 40, 2583-2591.

14. Gerardi, M.H. Wastewater Bacteria; John Wiley \& Sons: Hoboken, NJ, USA, 2006.

15. Ekster, A.; Ignasi, R.R. The effect of sludge age in the operational cost of Activated Sludge Systems. In Proceedings of the Water Environment Federation, WEFTEC 2003: Session 31 through 40; Water Environment Federation: Los Angeles, CA, USA, 2003; pp. 402-410.

16. Andreadakis, A.D. Nitrification-denitrification and activated sludge settlement. Environ. Technol. 1993, 14, 615-627.

17. Chan, L.; Leu, S.Y.; Rosso, D.; Stenstrom, M.K. The relationship between mixed-liqour particle size and solids retention time in the activated sludge process. Water Environ. Res. 2011, $83,2178-2186$.

18. Falas, P.; Andersen, H.R.; Ledin, A.; la Cour Jansen, J. Impact of solid retention time and nitrification capacity on the ability of activated sludge to remove pharmaceuticals. Environ. Technol. 2012, 33, 865-872.

19. Arceivala, S.J.; Asolerkar, S.R. Wastewater Treatment for Pollution Control and Reuse; Tata McGraw-Hill: New Delhi, India, 2007.

20. Kim, D.; Kim, K.Y.; Ryu, H.; Min, K.K.; Lee, S. Long term operation of pilot-scale biological nutrient removal process in treating municipal wastewater. Bioresour. Technol. 2009, 100, 3180-3184.

21. APHA. Standard Methods for the Examination of Water and Wastewater, 21st ed.; American Public Health Association (APHA): Washington, DC, USA, 2005.

22. Arceivala, S.J. Wastewater Treatment and Disposal: Engineering and Ecology in Pollution Control; Marcel Dekker Inc.: New York, NY, USA, 1981. 
23. Qasim, S.R. Wastewater Treatment Plants: Planning, Design and Operation; Holt, Rinehart and Winston: New York, NY, USA, 1985.

24. Design of Municipal Wastewater Treatment Plants; Water Environment Federation/American Society of Civil Engineers: Alexandria, VA, USA, 1982.

25. Mara, D. Domestic Wastewater Treatment in Developing Countries; Earthscan: London, UK, 2003.

26. Metcalf \& Eddy. Wastewater Engineering: Treatment and Reuse, 4th ed.; Metcalf \& Eddy, Inc.: New York, NY, USA, 2003.

27. Von Sperling, M.V.; Chernicharo, C.A.L. Biological Wastewater Treatment in Warm Climate Regions; IWA Publishing: London, UK, 2005; Volume 1.

28. Spellman, F.R. Handbook of Water and Wastewater Treatment Plant Operation; CRC Press: Boca Raton, FL, USA, 2003.

(C) 2015 by the authors; licensee MDPI, Basel, Switzerland. This article is an open access article distributed under the terms and conditions of the Creative Commons Attribution license (http://creativecommons.org/licenses/by/4.0/). 